\section{Kidney \\ Blood Pressure Research}

\title{
The Endothelial Nitric Oxide Synthase Gene Polymorphism is Associated with the Susceptibility to Immunoglobulin a Nephropathy in Chinese Population
}

\author{
Jie Gao ${ }^{a}$ Meng Wang ${ }^{b}$ Linting Wei ${ }^{a}$ Dan Niuc Jiali Weid ${ }^{c}$ Yan Ou ${ }^{a}$ Tianbo Jin ${ }^{\mathrm{e}}$ \\ Qiaoling Yu ${ }^{f}$ Xinghan Liu ${ }^{b}$ Tian Tian $^{b}$ Cong Dai ${ }^{b}$ Rongguo Fu ${ }^{a}$ Li Wang \\ a'Department of Nephrology, Second Affiliated Hospital of Xi'an; 'bepartment of Oncology, Second \\ Affiliated Hospital of Xi'an; 'Department of Nephrology, First Affiliated Hospital of Xi'an, Jiaotong \\ University, Xi'an; 'Department of Nephrology, Hainan general hospital, Haikou, eNational Engineering \\ Research Center for Miniaturized Detection Systems, School of Life Sciences, Northwest University, \\ Xi'an, 'Department of Pathology, Second Affiliated Hospital of Xi'an Jiaotong University, Xi'an, China
}

\section{Key Words}

Endothelial nitric oxide synthase • Rs1799983 • Rs2070744 • Single-nucleotide polymorphisms - IgA nephropathy • Risk

\begin{abstract}
Background/Aims: Endothelial nitric oxide synthase (eNOS) is one of the most important enzymes for producting nitric oxide (NO), which regulate the function of many organs and cells. The single nucleotide polymorphisms (SNPs) of eNOS were found to be associated with many kidney diseases. However, it is lack of relevant studies to evaluate the associations between eNOS polymorphisms and immunoglobulin A nephropathy (IgAN). This case-control study aimed to evaluate the relationship between eNOS polymorphisms and IgAN. Methods: We recruited 351 IgAN patients and 310 age- and sex-matched healthy controls from Northwest China. Sequenom MassARRAY was used to detect the genotypes of two common eNOS SNPs (rs1799983 and rs2070744). Odds ratios (ORs) and 95\% confidence intervals (95\% CIs) were calculated by the Chi square test to evaluate the associations between eNOS and IgAN. Phase 2.1 was used to conduct haplotype analysis. Results: In the overall analysis, we found that the rs 1799983 polymorphism was associated with a decreased risk of IgAN (G/T vs. $G / G$ : $O R=0.57,95 \% C I=0.34-0.96 ; G / T+T / T$ vs. $G / G: O R=0.52,95 \% C I=0.31-0.86 ; G / T$ vs.
\end{abstract}

J. Gao, M. Wang, and L. Wei contributed equally and therefore share first authorshipto.

Li Wang, MD, PHD
Department of Nephrology, Second Affiliated Hospital of Xi'an Jiaotong University, Xi'an (China), Tel. +86-29-8767-9917, Fax +86-29-8767-9917,

E-Mail lemonwine@126.com 


\section{Kidney Blood Pressure Research}

G/G-T/T: OR=0.60, 95\%CI=0.36-0.99; Log-additive model: OR=0.48, 95\%CI=0.30-0.78). Haplotype analysis indicated that $\mathrm{T}_{\mathrm{rs} 1799983} \mathrm{C}_{\mathrm{rs} 2070744}$ is a protective factor against IgAN (OR=0.62, $95 \% \mathrm{CI}=0.42-0.92$ ). However, no significant differences were found between the two SNPs (rs1799983 and rs2070744) and clinical features (age, sex, blood pressure, and Lee's grade) of IgAN. Conclusion: The eNOS gene rs1799983 polymorphism and $\mathrm{T}_{\mathrm{rs} 1799983} \mathrm{C}_{\mathrm{rs} 2070744}$ haplotype may reduce the risk of IgAN in Chinese populations.

\section{Introduction}

Immunoglobulin A nephropathy (IgAN), also known as Berger's disease because it was first described by Berger and Hinglais [1], is the most common primary glomerulonephritis worldwide and the most common disease leading to end-stage renal disease (ESRD) [2]. The disease occurs at any age, particularly among the adolescents and young adults with a male-to-female ratio 2:1 or 3:1 [3]. Until now, four processes were suggested to be involved in IgAN development. Firstly, higher levels of IgA1 with galactose-deficient O-glycans in the hinge-region were observed in IgAN patients (Hit 1). Secondly, antibodies recognized these antigenic determinants to form and deposit immune complexes (Hit 2 and 3). Finally, these immune complexes activate mesangial cells to proliferate and secret extracellular matrix, cytokines, and chemokines, which lead to renal injury (Hit 4) [4]. Genetic factors have been demonstrated to be crucial in the development and progression of IgAN. Genome-wide association studies indicated that multiple gene polymorphisms were associated with the susceptibility to IgAN [5-7].

Nitric oxide (NO) is an endothelium-derived relax factor that can dilate blood vessels, relax vascular smooth muscle, and inhibit endothelial cell proliferation and platelet aggregation [8]. Its synthesis depends on NO synthase (NOS), which oxidizes L-arginine to L-citrulline. There are three important informs of NOS in humans: neuronal NO synthase, inducible NO synthase, and endothelial NO synthase (eNOS) [8, 9]. Endothelial cells that produce NO rely on eNOS, a multi-domain enzyme that uses several cofactors including tetrahydrobiopterin, nicotinamide-adenine -dinucleotide phosphate, flavin adenine dinucleotide, and flavin mononucleotide $[8,10]$. The human eNOS gene is located on chromosome $7 q 35-36$, with a length of $21 \mathrm{~kb}$ containing 25 introns and 26 exons [11]. eNOS is related to the dysfunction of endothelial cells, and normal eNOS function promotes pathological vascular repair, and protects against complications such as hypertension, atherosclerosis, and diabetes [10].

NO, produced by renal tubular epithelial cells and mesangial cells, plays an important role in regulating renal hemodynamic and tubular function [11, 12]. Decreased NO levels may be important in the progression of renal disease [13]. Polymorphisms in eNOS have been demonstrated to be associated with NO levels in the serum [14]. Additionally, several studies showed that eNOS polymorphisms were related to many renal diseases, including diabetic nephropathy (DN) [15-17], polycystic kidney disease [11], and lupus nephritis [18]. However, the relationship between single-nucleotide polymorphisms (SNPs) of eNOS and IgAN remains unclear. We conducted a case-control study, selecting two common loci in eNOS gene, G894T missense mutation (rs1799983) and T786C (rs2070744), to evaluate the influence of eNOS on IgAN.

\section{Materials and Methods}

Ethics statement

The study protocol was approved by the ethics committee of the Second Affiliated Hospital of Xi'an Jiaotong University. All participants signed informed consents before they were in for this experiment. 


\section{Kidney Blood Pressure Research}

Gao et al.: eNOS Gene Polymorphisms and IgAN Risk

Table 1. Primers used for this study

\begin{tabular}{|c|c|c|c|}
\hline SNP_ID & 1st-PCRP & 2nd-PCRP & UEP_SEQ \\
\hline rs1799983 & ACGTTGGATGACCTCAAGGACCAGCTCGG & ACGTTGGATGAAACGGTCGCTTCGACGTG & GCAGGCCCCAGATGA \\
\hline rs2070744 & ACGTTGGATGTGTCATTCAGTGACGCACGC & ACGTTGGATGACCAGGGCATCAAGCTCTTC & CAAGCTCTTCCCTGGC \\
\hline
\end{tabular}

\section{Population}

This hospital-based study enrolled patients with IgAN from Northwestern China who visited to the First and Second Affiliated Hospital of Xi'an Jiaotong University during March 2009 to April 2014. All patients were pathologically confirmed by renal biopsy. The age- and sex-matched healthy controls were recruited from healthy examinations in the same hospitals during the same period. Participants were excluded if they had other renal diseases such as DN, lupus nephritis, and other secondary IgAN, or if they were not Han Chinese. Demographic and clinical characteristics were collected from the medical records and a self-administered questionnaire was completed by the participants. The information including age, gender, $24-\mathrm{h}$ urine protein, blood pressure, serum creatinine level, blood urea nitrogen, serum albumin level, serum cholesterol level, serum IgA level, serum C3 level, and histopathological grade (Lee's classification) were recorded. Lee's classification is a method for determining pathological type, it relies on the severity of glomerular and interstitial lesions (I: glomerular, tubular and interstitial lesions are normal; II: focal hyperplasia in glomerular and tubular lesions, and interstitial lesions are normal; III: diffuse hyperplasia in glomerular lesions, focal atrophy in renal tubular lesions and interstitial edema; IV: less than 45\% glomerular lesions with crescent and sclerosis, multifocal atrophy, and fibrosis in tubular and interstitial lesions; V: more than $45 \%$ glomerular lesions with crescent and sclerosis, and tubular and interstitial lesions are more serious than those of IV). Additionally, participants lacking detailed information were excluded.

\section{DNA extraction and genotyping}

Tubes containing ethylene diaminetetraacetic acid were used to collect approximately $2 \mathrm{~mL}$ peripheral venous blood samplesfrom each participant. The serum was collected by centrifuging the whole blood at $1500 \mathrm{rpm}$ for $10 \mathrm{~min}$ and then stored at $-80^{\circ} \mathrm{C}$ until use. The DNA was extracted according to the instructions of the GoldMag DNA Purification Kit (GoldMag Co. Ltd, Xi'an City, China). The purity and concentration of DNA were measured utilizing an ultraviolet spectrophotometer (Nanodrop, Thermo Scientific, Waltham, MA, USA). Sequenom MassARRAY RS1000 was used to detect the genotypes of two common eNOS SNPs (rs1799983 and rs2070744). The primers used for each SNP are listed in Table 1. SequenomTyper 3.0 Software (San Diego, CA, USA) was used for data analyses.

\section{Statistical analyses}

Microsoft Excel (version 2007, Microsoft, Redmond, WA, USA) was used for data analysis. SPSS software (version 21.0, SPSS, Inc., Chicago, IL, USA) was used for statistical analyses. Hardy-Weinberg equilibrium was tested by Fisher's exact test for each SNP in controls. The Student $t$-test or the Chi square test $\left(\chi^{2}\right.$ test) was used to examine the differences in distributions of demographic characteristics between patients and controls. Odds ratios (ORs) and 95\% confidence intervals ( $95 \%$ CIs) were calculated by $\chi^{2}$ test to evaluate the associations between eNOS and IgAN. All tests were two-tailed and $P<0.05$ was considered to indicate statistical difference. Five genetic models were used in our study: co-dominant model (including homozygote model and heterozygote model), recessive model, dominant model, over-dominant model, and Log-additive model. Phase2.1 software (downloaded from http://stephenslab.uchicago.edu/phase/download.html) was used to evaluate haplotypes and the $\chi^{2}$ test was used to estimate differences in each haplotype.

\section{Results}

Characteristics of the study participants

The study included 351 patients with IgAN (229 males and 122 females, mean age of 32 \pm 11.9 years) and 310 age- and sex-matched healthy controls (186 males and 124 females, 


\section{Kidney Blood Pressure Research}

Table 2. Genotype of eNOS polymorphisms among the cases and controls and the associations with IgAN risk (before and after adjusted by age and gender)

\begin{tabular}{|c|c|c|c|c|c|c|c|c|c|}
\hline \multirow{2}{*}{ Model } & \multirow{2}{*}{ Genotype } & \multirow{2}{*}{ Control } & \multirow{2}{*}{ Case } & \multicolumn{2}{|c|}{ Before adjusted } & \multicolumn{2}{|c|}{ After adjusted $\dagger$} & \multirow{2}{*}{ AIC } & \multirow{2}{*}{ BIC } \\
\hline & & & & OR $(95 \% \mathrm{CI})$ & $\mathrm{P}$-value & OR $(95 \% \mathrm{CI})$ & P-value & & \\
\hline rs1799983* & \multicolumn{9}{|c|}{ HWE $P=0.86$} \\
\hline \multirow{3}{*}{ Codominant } & $\mathrm{G} / \mathrm{G}$ & $239(77.1 \%)$ & $290(82.9 \%)$ & 1.00 & & 1.00 & & & \\
\hline & $\mathrm{G} / \mathrm{T}$ & $66(21.3 \%)$ & $60(17.1 \%)$ & $0.75(0.51-1.11)$ & 0.0078 & $0.57(0.34-0.96)$ & $<0.0001$ & 578.3 & 600.8 \\
\hline & $\mathrm{T} / \mathrm{T}$ & $5(1.6 \%)$ & $0(0 \%)$ & - & & - & & & \\
\hline \multirow{2}{*}{ Dominant } & $G / G$ & $239(77.1 \%)$ & $290(82.9 \%)$ & 1.00 & \multirow{2}{*}{0.064} & 1.00 & \multirow{2}{*}{0.01} & \multirow{2}{*}{583.7} & \multirow{2}{*}{601.6} \\
\hline & $\mathrm{G} / \mathrm{T}-\mathrm{T} / \mathrm{T}$ & $71(22.9 \%)$ & $60(17.1 \%)$ & $0.70(0.47-1.02)$ & & $0.52(0.31-0.86)$ & & & \\
\hline \multirow{2}{*}{ Recessive } & $\mathrm{G} / \mathrm{G}-\mathrm{G} / \mathrm{T}$ & $305(98.4 \%)$ & $350(100 \%)$ & 1.00 & & 1.00 & & \multirow{2}{*}{-} & \multirow{2}{*}{-} \\
\hline & $\mathrm{T} / \mathrm{T}$ & $5(1.6 \%)$ & $0(0 \%)$ & - & & & & & \\
\hline \multirow{2}{*}{ Overdominant } & $\mathrm{G} / \mathrm{G}-\mathrm{T} / \mathrm{T}$ & $244(78.7 \%)$ & $290(82.9 \%)$ & 1.00 & \multirow{2}{*}{0.18} & 1.00 & \multirow{2}{*}{0.044} & \multirow{2}{*}{586.2} & \multirow{2}{*}{604.2} \\
\hline & $\mathrm{G} / \mathrm{T}$ & $66(21.3 \%)$ & $60(17.1 \%)$ & $0.76(0.52-1.13)$ & & $0.60(0.36-0.99)$ & & & \\
\hline Log-additive & $--\cdot$ & -.- & -.- & $0.66(0.46-0.95)$ & 0.025 & $0.48(0.30-0.78)$ & 0.0027 & 581.3 & 599.2 \\
\hline rs2070744 & \multicolumn{9}{|c|}{ HWE $\mathrm{P}=0.80$} \\
\hline \multirow{3}{*}{ Codominant } & $\mathrm{C} / \mathrm{C}$ & $256(82.6 \%)$ & $287(81.8 \%)$ & 1.00 & \multirow{3}{*}{0.85} & 1.00 & & \multirow{3}{*}{591.4} & \multirow{3}{*}{613.9} \\
\hline & $\mathrm{C} / \mathrm{T}$ & $51(16.4 \%)$ & $59(16.8 \%)$ & $1.03(0.68-1.56)$ & & $1.21(0.71-2.07)$ & 0.63 & & \\
\hline & $\mathrm{T} / \mathrm{T}$ & $3(1 \%)$ & $5(1.4 \%)$ & $1.49(0.35-6.28)$ & & $1.89(0.31-11.35)$ & & & \\
\hline \multirow{2}{*}{ Dominant } & $\mathrm{C} / \mathrm{C}$ & $256(82.6 \%)$ & $287(81.8 \%)$ & 1.00 & \multirow{2}{*}{0.78} & 1.00 & 0.4 & 589.6 & 607.6 \\
\hline & $\mathrm{C} / \mathrm{T}-\mathrm{T} / \mathrm{T}$ & $54(17.4 \%)$ & $64(18.2 \%)$ & $1.06(0.71-1.58)$ & & $1.25(0.74-2.10)$ & & & \\
\hline Recessive & $\mathrm{C} / \mathrm{C}-\mathrm{C} / \mathrm{T}$ & $307(99 \%)$ & $346(98.6 \%)$ & 1.00 & 0.59 & 1.00 & 0.51 & 589.9 & 607.9 \\
\hline Recessive & $\mathrm{T} / \mathrm{T}$ & $3(1 \%)$ & $5(1.4 \%)$ & $1.48(0.35-6.24)$ & 0.59 & $1.82(0.30-10.92)$ & & & \\
\hline & $\mathrm{C} / \mathrm{C}-\mathrm{T} / \mathrm{T}$ & $259(83.5 \%)$ & $292(83.2 \%)$ & 1.00 & & 1.00 & 0.5 & 589.9 & 607.8 \\
\hline Overdominant & $\mathrm{C} / \mathrm{T}$ & $51(16.4 \%)$ & $59(16.8 \%)$ & $1.03(0.68-1.55)$ & 0.9 & $1.20(0.70-2.05)$ & & & \\
\hline Log-additive & -- & --- & --- & $1.07(0.75-1.54)$ & 0.7 & $1.25(0.78-2.00)$ & 0.35 & 589.4 & 607.4 \\
\hline
\end{tabular}

mean age of $35 \pm 12.6$ years), details as shown in our previous studies [19-21]. There were no statistically significant differences between the two groups in terms of age and sex $(P>0.05)$.

Association between eNOS polymorphisms and IgAN risk

The genotype frequency distributions of the two selected SNPs (rs1799983 and rs2070744) are shown in Table 2. The detection rates of genotypes were greater than $95 \%$, and only one patient's information was missing for the rs1799983 polymorphism. Both SNPs in the controls were in Hardy-Weinberg equilibrium $(P=0.86$, and $P=0.80$, respectively). Rs1799983 was associated with a reduced risk of IgAN in all genetic models, except for the heterozygote model and recessive model (G/T vs. G/G: OR=0.57, 95\%CI $=0.34-0.96$, $P<0.0001 ; \mathrm{G} / \mathrm{T}+\mathrm{T} / \mathrm{T}$ vs. G/G: $\mathrm{OR}=0.52,95 \% \mathrm{CI}=0.31-0.86, P=0.01 ; \mathrm{G} / \mathrm{T}$ vs. G/G-T/T: $\mathrm{OR}=0.60$, 95\%CI=0.36-0.99, $P=0.044$; Log-additive model: $\mathrm{OR}=0.48,95 \% \mathrm{CI}=0.30-0.78, P=0.0027$ ). However, no significant results were found for the association between rs2070744 and IgAN (all genetic models, $P>0.05$ ).

Difference in allele frequencies of eNOS in cases and controls

The allele frequencies of rs1799983 and rs2070744 are shown in Table 3.The frequency of rs1799983 $\mathrm{T}$ allele in IgAN patients was significantly lower than in the healthy control group (OR=0.67, 95\%CI=0.47-0.96, $P=0.028$ ). However, there was no statistically significant difference in the frequency distribution of the rs2070744 allele between IgAN patients and controls $(P=0.695)$.

\section{Haplotype analysis of eNOS polymorphisms and IgAN risk}

We further conducted haplotype analysis to evaluate the effect of the interaction of rs1799983 and rs2070744 on IgAN. The results showed that people with the ${ }_{\text {rs1799983 }} \mathrm{C}$ rs2070744 haplotype had a lower risk for IgAN than those who had the $\mathrm{G}_{\mathrm{rs} 1799983} \mathrm{C}_{\mathrm{rs} 2070744}$ haplotype (OR=0.62, 95\% CI $=0.42-0.92, P=0.017$, shown in Table 4). 


\section{Kidney Blood Pressure Research}

Table 3. Allele frequencies of eNOS in case and control and the association with IgAN risk

\begin{tabular}{lcccccccc}
\hline \multirow{2}{*}{ SNP ID } & \multicolumn{9}{c}{ Allele } & \multicolumn{2}{c}{ Case } & Control & OR (95\% CI) & P value \\
\cline { 2 - 10 } & A & B & A count $(\%)$ & B count $(\%)$ & A count $(\%)$ & B count $(\%)$ & & \\
\hline rs1799983 & T & G & $60(8.6 \%)$ & $640(91.4 \%)$ & $76(12.3 \%)$ & $544(87.7 \%)$ & $0.67(0.47-0.96)$ & 0.028 \\
rs2070744 & T & C & $69(9.8 \%)$ & $633(90.2 \%)$ & $57(9.2 \%)$ & $563(90.8 \%)$ & $1.08(0.75-1.56)$ & 0.695 \\
\hline
\end{tabular}

SNP: Single-nucleotide polymorphism; A: the minor allele; B: the major allele; OR: odds ratio; 95\% CI: 95\% confidence interval.

Table 4. The haplotype frequencies of eNOS polymorphisms and IgAN risk

\begin{tabular}{cccccc}
\hline & rs1799983 & rs2070744 & Freq & OR $(95 \% \mathrm{CI})$ & P-value \\
\hline 1 & $\mathrm{G}$ & $\mathrm{C}$ & 0.805 & 1.00 & $\cdots-$ \\
2 & $\mathrm{~T}$ & $\mathrm{C}$ & 0.0997 & $0.62(0.42-0.92)$ & 0.017 \\
3 & $\mathrm{G}$ & $\mathrm{T}$ & 0.092 & $0.96(0.64-1.45)$ & 0.86 \\
rares & - & - & 0.0034 & $11.56(0.00-556329683899.66)$ & 0.85 \\
\hline \multicolumn{7}{l}{ OR: odds ratio: 95\% CI: 95\% confidence interval. }
\end{tabular}

Table 5. Subgroup analysis by clinical parameters for the association between eNOS SNPs and IgAN patients

\begin{tabular}{|c|c|c|c|c|c|c|c|c|}
\hline \multirow[t]{2}{*}{ Variables } & \multicolumn{4}{|c|}{ rs1799983* } & \multicolumn{4}{|c|}{ rs2070744 } \\
\hline & $\begin{array}{l}\text { G/G } \\
(\%)\end{array}$ & $\mathrm{G} / \mathrm{T}(\%)$ & $\mathrm{P}$ & OR $(95 \% \mathrm{CI})$ & $\mathrm{C} / \mathrm{C}(\%)$ & $\mathrm{C} / \mathrm{T}-\mathrm{T} / \mathrm{T}(\%)$ & $P$ & OR $(95 \% \mathrm{CI})$ \\
\hline \multicolumn{9}{|c|}{ Gender } \\
\hline Female & $\begin{array}{c}103 \\
(84.4 \%)\end{array}$ & $19(15.6 \%)$ & & 1.00 (reference) & $96(78.7 \%)$ & $26(21.3 \%)$ & & 1.00 (reference) \\
\hline Male & $187(82 \%)$ & $41(18 \%)$ & 0.57 & $1.19(0.66-2.15)$ & $191(83.4 \%)$ & $38(16.6 \%)$ & 0.28 & $0.73(0.42-1.28)$ \\
\hline \multicolumn{9}{|c|}{ Urine protein $(\mathrm{g} / 24 \mathrm{~h})$} \\
\hline$<3.5$ & $228(83.8 \%)$ & $\begin{array}{c}44 \\
(16.2 \%)\end{array}$ & & 1.00 (reference) & $219(80.5 \%)$ & $53(19.5 \%)$ & & 1.00 (reference) \\
\hline$\geq 3.5$ & $62(79.5 \%)$ & $16(20.5 \%)$ & 0.37 & $\begin{array}{l}1.34(0.71- \\
2.53)\end{array}$ & $68(86.1 \%)$ & $11(13.9 \%)$ & 0.26 & $0.67(0.33-1.35)$ \\
\hline \multicolumn{9}{|c|}{ Blood Pressure (mmHg) } \\
\hline$<140 / 90$ & 165 (85.1\%) & $29(14.9 \%)$ & & 1.00 (reference) & $155(79.9 \%)$ & $39(20.1 \%)$ & & 1.00 (reference) \\
\hline$\geq 140 / 90$ & $125(80.1 \%)$ & $31(19.9 \%)$ & 0.22 & $1.41(0.81-2.46)$ & $132(84.1 \%)$ & $25(15.9 \%)$ & 0.31 & $0.75(0.43-1.31)$ \\
\hline \multicolumn{9}{|c|}{ Lee's grades } \\
\hline $\mathrm{I}+\mathrm{II}+\mathrm{III}$ & $217(83.5 \%)$ & $43(16.5 \%)$ & & 1.00 (reference) & $\begin{array}{c}215 \\
(82.7 \%)\end{array}$ & $45(17.3 \%)$ & & 1.00 (reference) \\
\hline $\mathrm{IV}+\mathrm{V}$ & $\begin{array}{c}73 \\
(81.1 \%) \\
\end{array}$ & $17(18.9 \%)$ & 0.61 & $\begin{array}{c}1.18 \\
(0.63-2.19) \\
\end{array}$ & $72(79.1 \%)$ & $19(20.9 \%)$ & 0.45 & $1.26(0.69-2.30)$ \\
\hline
\end{tabular}

Association between eNOS polymorphisms and clinical parameters of IgAN patients

IgA nephropathy is more common in males than in females. And, blood pressure, 24-h urine protein, and Lee's grade are important for the prognosis of IgAN. Thus, we further performed subgroup analyses according to patient sex, blood pressure, 24-h urine protein, and Lee's classification. However, we found no correlation between sex, blood pressure, 24-h urinary protein, or Lee's classification in the two SNPs (all genetic models, $P>0.05$, shown in Table 5).

\section{Discussion}

Endothelial cell function and vascular tension can become unregulated in many organs, including the kidney. Abnormal levels of nitric oxide can lead to endothelial dysfunction, which may promote the occurrence and development of difference diseases, such as atherosclerosis, hypertension, hyperlipidemia, diabetes, and thrombosis disease $[8,16]$. 


\section{Kidney Blood Pressure Research}

eNOS is mainly distributed in large and medium blood vessels, catalyzing the synthesis of NO from L-arginine and oxygen molecules [8]. The expression of eNOS can be influenced by transcription, mRNA stability, and phosphorylation level. Shear stress, exercise, and hypoxia were found to up-regulate the level of eNOS by enhancing transcription [22]. Additionally, lipopolysaccharide and tumor necrosis factor- $\alpha$ down regulated eNOS gene expression by damaging the stability of eNOS-mRNAs [22]. The phosphorylation and dephosphorylation of serine and threonine are important in the regulation of eNOS expression [23]. Statins, widely used in the treatment of cardiovascular diseases, were found to provide protection against cardiovascular diseases by increasing the bioavailability of NO via enhancing eNOS gene function [24]. NO can relax the efferent and afferent artery, increase glomerular filtration rate, and regulate renal sodium excretion $[16,25]$. The level of serum NO was decreased in patients with ESRD, further promoting the occurrence of cardiovascular events, thus aggravating kidney injury [26]. Vascular endothelial damage in patients with ESRD reduced the synthesis of NO via disrupting the normal function of eNOS [27]. Abnormal hemodynamic function in the glomerulus may be involved in the pathogenesis of IgAN. Thus, we hypothesized that eNOS plays a role in IgAN risk. And, considering that several clinical and histological parameters such as severe proteinuria , arterial hypertension, hyperuricemia and glomerular sclerosis or tubulointerstitial scarring at renal biopsy may influence the progression [28-30], so that we further conducted subgroup analysis by clinical characteristics of IgAN patients.

The G894T (rs1799983) missense mutation in exon 7 leads to a single amino acid substitution from glutamate to aspartate at position 298 [15]. The T786C (rs2070744) polymorphism in the promoter of the eNOS gene at the eNOS-786 site results in the replacement of thymidine with cytosine, leading to compromised production of the eNOS enzyme in vivo by reducing promoter activity [15]. These two SNPs were demonstrated to be associated with various renal diseases. A recent meta-analysis suggested that the rs1799983 GG genotype is a protective factor for ESRD [31]. Studies performed in DN patients showed associations between eNOS SNPs and DN risk and prognosis. A meta-analysis conducted by Zhang et al. indicated that rs1799983 increases DN risk, while the relationship between rs2070744 and DN was not statistically significant [15]. However, few studies have focused on eNOS polymorphisms and IgAN. Zhang et al. found that eNOS G894T polymorphisms were correlated with high blood urea nitrogen and pathologic classification in IgAN patients, which may predict a poor prognosis of IgAN [32]. Rodríguez-Pérez et al. found no significant difference between G894T SNP and IgAN. However, the simultaneous presence of ACE DD variants and G894T GG variants was related to an unfavorable outcome as compared to other combinations [hazard ratio ranging from 4.7 (95\% CI 1.52-14.33) to 8.4 (95\% CI 2.45-29.10)] [33]. The results showed that the rs1799983 T allele may decrease IgAN risk, which is inconsistent with the results of Zhang et al. and Rodríguez-Pérez et al [32, 33]. We included 351 IgAN patients and 310 controls, which is a greater number of subjects than in previous studies, making our results more reliable. We first evaluated the association between the rs2070744 polymorphism and IgAN and the detailed clinical characteristics of IgAN patients were also analyzed. We further conducted haplotype analyses and found

that the $\mathrm{T}_{\mathrm{rs1799983}} \mathrm{C}_{\mathrm{rs} 2070744}$ haplotype may be a protective factor for IgAN compared to the $\mathrm{G}$ ${ }_{\text {rs1799983 }} \mathrm{C}_{\text {rs2070744 }}$ haplotype. This is the first study to evaluate the effect of the interaction of these two SNPs on IgAN risk. Several genome-wide association studies (GWAS) have also revealed some SNPs that associated with IgAN susceptibility. Gharavi AG et al. found SNPs in major histocompatibility complex, CFHR1 and CFHR3 contribute to $4-7 \%$ of the IgAN variance and tenfold variation in person risk [34]. HLA-DQB1/DRB1, PSMB9/TAP1, DPA1/ DPB2, CFHR3/R1 and HORMAD2 were also suggested to be related to IgAN susceptibility [35]. Unfortunately, up to now, few GWAS studies have confirmed the association between eNOS polymorphisms and IgAN risk.

There were some limitations to this study. First, this was a single-center study, and thus bias is inevitable. More well-designed multi-center studies are needed to verify our results. Second, all participants were Han Chinese, which may restrict the large-scale application of 


\section{Kidney Blood Pressure Research}

our results to other ethnic groups. Third, the sample size of our study may not have been sufficiently large to identify differences in the subgroup analyses. Fourth, there were several clinical parameters, such as uric acid level, glomerular filtration rate, did not be analyzed because of lacking the data. Finally, this study was just focused on the different distribution of two SNPs in IgAN patients and health controls, so further functional studies and follow-up investigations are needed to perform in the future.

\section{Conclusion}

We found that the eNOS rs1799983 polymorphism and $\mathrm{T}_{\mathrm{rs} 1799983} \mathrm{C}_{\mathrm{rs} 2070744}$ haplotype might reduce the risk of IgAN in Chinese populations. However, additional well-designed large-scale studies are required to verify the molecular mechanisms of IgAN.

\section{Disclosure Statement}

The authors declare that they do not have any Disclosure Statements.

\section{Acknowledgements}

This work was supported by National Natural Science Foundation of China (No. $81470968,81100530)$ and the Science and technology project of Shaanxi Province (2014K 11- 02-04-05).

\section{References}

$>1$ Berger J, Hinglais N: Intercapillary deposits of IgA-IgG. J Urol Nephrol (Paris) 1968;74:694-695.

-2 Maixnerova D, Reily C, Bian Q Neprasova M, Novak J, Tesar V: Markers for the progression of IgA nephropathy. J Nephrol 2016;29:535-541.

3 Fabiano RC, Pinheiro SV, Simões E Silva AC: Immunoglobulin A nephropathy: a pathophysiology view. Inflamm Res 2016;65:757-770.

4 Kiryluk K, Li Y, Sanna-Cherchi S, Rohanizadegan M, Suzuki H, Eitner F, Snyder HJ, Choi M, Hou P, Scolari F, Izzi C, Gigante M, Gesualdo L, Savoldi S, Amoroso A, Cusi D, Zamboli P, Julian BA, Novak J, Wyatt RJ, Mucha K, Perola M, Kristiansson K, Viktorin A, Magnusson PK, Thorleifsson G, Thorsteinsdottir U, Stefansson K, Boland A, Metzger M, Thibaudin L, Wanner C, Jager KJ, Goto S, Maixnerova D, Karnib HH, Nagy J, Panzer U, Xie J, Chen N, Tesar V, Narita I, Berthoux F, Floege J, Stengel B, Zhang H, Lifton RP and Gharavi AG: Geographic differences in genetic susceptibility to IgA nephropathy: GWAS replication study and geospatial risk analysis. PLoS Genet 2012;8:e1002765.

5 Xie J, Shapiro S, Gharavi A: Genetic studies of IgA nephropathy: what have we learned from genome-wide association studies. Contrib Nephrol 2013;181:52-64.

6 Xu R, Feng S, Li Z, Fu Y, Yin P, Ai Z, Liu WT, Yu XQ, Li M: Polymorphism of DEFA in Chinese Han population with IgA nephropathy. Hum Genet 2014;133:1299-1309.

7 Li M, Foo JN, Wang JQ, Low HQ, Tang XQ, Toh KY, Yin PR, Khor CC, Goh YF, Irwan ID, Xu RC, Andiappan AK, Bei JX, Rotzschke O, Chen MH, Cheng CY, Sun LD, Jiang GR, Wong TY, Lin HL, Aung T, Liao YH, Saw SM, Ye K, Ebstein RP, Chen QK, Shi W, Chew SH, Chen J, Zhang FR, Li SP, Xu G, Tai ES, Wang L, Chen N, Zhang XJ, Zeng YX, Zhang H, Liu ZH, Yu XQ Liu JJ: Identification of new susceptibility loci for IgA nephropathy in Han Chinese. Nat Commun 2015;6:7270.

8 Napoli C, Ignarro LJ: Nitric oxide and pathogenic mechanisms involved in the development of vascular diseases. Arch Pharm Res 2009;32:1103-1108. 


\section{Kidney \\ Blood Pressure Research}

-9 Wang Y, Marsden PA: Nitric oxide synthases: biochemical and molecular regulation. Curr Opin Nephrol Hypertens 1995;4:12-22.

10 Siragusa M, Fleming I: The eNOS signalosome and its link to endothelial dysfunction. Pflugers Arch 2016;468:1125-1137.

11 Xue C, Zhou CC, Sun LJ, He LL, Xu CG, Dai B, Mei CL: Effects of endothelial nitric oxide synthase gene on end stage renal disease progression in autosomal dominant polycystic kidney disease. Nephrology (Carlton) 2014;19:630-637.

12 Yun Z, Yu-Ping Y, Zong-Wu T, Yang S, Fang Y, Fang S: Association of endothelial nitric oxide synthase gene polymorphisms with end-stage renal disease: a systematic review and meta-analysis. Ren Fail 2014;36:987-993.

13 Baylis C, Mitruka B, Deng A: Chronic blockade of nitric oxide synthesis in the rat produces systemic hypertension and glomerular damage. J Clin Invest 1992;90:278-281.

-14 Tsukada T, Yokoyama K, Arai T, Takemoto F, Hara S, Yamada A, Kawaguchi Y, Hosoya T, Igari J:Evidence of association of the ecNOS gene polymorphism with plasma NO metabolite levels in humans. Biochem Biophys Res Commun 1998;245:190-193.

15 Zhang Y, Xiao HQ Zeng XT, Zuo HX, Xu YC: Associations between endothelial nitric oxide synthase polymorphisms and risk of diabetic nephropathy: an updated meta-analysis. Ren Fail 2015;37:312-326.

16 Dellamea BS, Leitao CB, Friedman R, Canani LH: Nitric oxide system and diabetic nephropathy. Diabetol Metab Syndr 2014;6:17.

17 Ahluwalia TS, Ahuja M, Rai TS, Kohli HS, Sud K, Bhansali A, Khullar M: Endothelial nitric oxide synthase gene haplotypes and diabetic nephropathy among Asian Indians. Mol Cell Biochem 2008;314:9-17.

18 Li X, An J, Guo R, Jin Z, Li Y, Zhao Y, Lu F, Lian H, Liu P, Zhao Y, Jin X: Association of the genetic polymorphisms of the ACE gene and the eNOS gene with lupus nephropathy in northern Chinese population. BMC Med Genet 2010;11:94.

19 Gao J, Wei L, Liu X, Wang L, Niu D, Jin T, Yao G, Wang M, Yue Q, Fu R: Association between IFN- $\gamma$ gene polymorphisms and IgA nephropathy in a Chinese Han population. Kidney Blood Press Res 2017;42:136144.

20 Gao J, Wei L, Fu R, Wei J, Niu D, Wang L, Ge H, Yu Q, Wang M, Liu X, Zhang W: Association of Interleukin-10 Polymorphisms (rs1800872, rs1800871, and rs1800896) with Predisposition to IgA Nephropathy in a Chinese Han Population: A Case-Control Study. Kidney Blood Press Res 2017;42:89-98.

21 Gao J, Liu X, Wei L, Niu D, Wei J, Wang L, Ge H, Wang M, Yu Q Jin T, Tian T, Dai Z, Fu R: Genetic variants of MCP-1 and CCR2 genes and IgA nephropathy risk. Oncotarget 2016;7:77950-77957.

22 Chatterjee A, Black SM, Catravas JD: Endothelial nitric oxide (NO) and its pathophysiologic regulation. Vascul Pharmacol 2008;49:134-40.

23 Bauer PM, Fulton D, Boo YC, Sorescu GP, Kemp BE, Jo H, Sessa WC: Compensatory phosphorylation and protein-protein interactions revealed by loss of function and gain of function mutants of multiple serine phosphorylation sites in endothelial nitric-oxide synthase. J Biol Chem 2003;278:14841-14849.

24 Hsu CP, Zhao JF, Lin SJ, Shyue SK, Guo BC, Lu TM, Lee TS: Asymmetric Dimethylarginine Limits the Efficacy of Simvastatin Activating Endothelial Nitric Oxide Synthase. J Am Heart Assoc 2016;5:e003327.

-25 Mount PF, Power DA: Nitric oxide in the kidney: functions and regulation of synthesis. Acta Physiol (Oxf) 2006;187:433-446.

26 Baylis C: Nitric oxide deficiency in chronic kidney disease. Am J Physiol Renal Physiol 2008;294:F1-9.

27 Reddy YS, Kiranmayi VS, Bitla AR, Krishna GS, Rao PV, Sivakumar V: Nitric oxide status in patients with chronic kidney disease. Indian J Nephrol 2015;25:287-291.

28 Caliskan Y, Ozluk Y, Celik D, Oztop N, Aksoy A, Ucar AS, Yazici H, Kilicaslan I, Sever MS: The Clinical Significance of Uric Acid and Complement Activation in the Progression of IgA Nephropathy. Kidney Blood Press Res 2016;41:148-157.

29 Tan M, Li W, Zou G, Zhang C, Fang J: Clinicopathological features and outcomes of IgA nephropathy with hematuria and/or minimal proteinuria. Kidney Blood Press Res 2015;40:200-206.

30 Worawichawong S, Worawichawong S, Radinahamed P, Muntham D, Sathirapongsasuti N, Nongnuch A, Assanatham M, Kitiyakara C: Urine Epidermal Growth Factor, Monocyte Chemoattractant Protein-1 or Their Ratio as Biomarkers for Interstitial Fibrosis and Tubular Atrophy in Primary Glomerulonephritis. Kidney Blood Press Res 2016;41:997-1007. 


\section{Kidney \\ Blood Pressure Research}

31 Zhou TB, Yin SS: Association of endothelial nitric oxide synthase Glu298Asp gene polymorphism with the risk of end-stage renal disease. Ren Fail 2013;35:573-578.

-32 Zhu X, Kong D, Zhang L, Sun Y, Na S, Han C, Jin X: Correlation analysis of angiotensin-converting enzyme, angiotensinogen, and endothelial nitric oxide synthase gene polymorphisms and the progression of immunoglobulin A nephropathy/membranous nephropathy. Hum Pathol 2013;44:2806-2813.

-33 Rodriguez-Perez JC, Macias-Reyes A, Jimenez-Sosa A, Companioni O, Rodriguez-Esparragon FJ, Cobo MA, Checa-Andrés MD, Palop-Cubillo L, Alonso A, Torres A: A synergistic association of ACE I/D and eNOS G894T gene variants with the progression of immunoglobulin A nephropathy - a pilot study. Am J Nephrol 2009;30:303-309.

-34 Gharavi AG, Kiryluk K, Choi M, Li Y, Hou P, Xie J, Sanna-Cherchi S, Men CJ, Julian BA, Wyatt RJ, Novak J, He JC, Wang H, Lv J, Zhu L, Wang W, Wang Z, Yasuno K, Gunel M, Mane S, Umlauf S, Tikhonova I, Beerman I, Savoldi S, Magistroni R, Ghiggeri GM, Bodria M, Lugani F, Ravani P, Ponticelli C, Allegri L, Boscutti G, Frasca G, Amore A, Peruzzi L, Coppo R, Izzi C, Viola BF, Prati E, Salvadori M, Mignani R, Gesualdo L, Bertinetto F, Mesiano P, Amoroso A, Scolari F, Chen N, Zhang H, Lifton RP: Genome-wide association study identifies susceptibility loci for IgA nephropathy. Nat Genet 2011;43:321-327.

-35 Kiryluk K, Li Y, Sanna-Cherchi S, Rohanizadegan M, Suzuki H, Eitner F, Snyder HJ, Choi M, Hou P, Scolari F, Izzi C, Gigante M, Gesualdo L, Savoldi S, Amoroso A, Cusi D, Zamboli P, Julian BA, Novak J, Wyatt RJ, Mucha K, Perola M, Kristiansson K, Viktorin A, Magnusson PK, Thorleifsson G, Thorsteinsdottir U, Stefansson K, Boland A, Metzger M, Thibaudin L, Wanner C, Jager KJ, Goto S, Maixnerova D, Karnib HH, Nagy J, Panzer U, Xie J, Chen N, Tesar V, Narita I, Berthoux F, Floege J, Stengel B, Zhang H, Lifton RP, Gharavi AG: Geographic differences in genetic susceptibility to IgA nephropathy: GWAS replication study and geospatial risk analysis. PLoS Genet 2012;8:e1002765. 